\title{
Net-zero emissions targets are vague: three ways to fix
}

Authors:

Joeri Rogelj(1,2,*), Oliver Geden(3), Annette Cowie(4,5), Andy Reisinger(6)

(1) Grantham Institute - Climate Change \& the Environment, Imperial College London, London, UK

(2) International Institute for Applied Systems Analysis, Laxenburg, Austria

(3) German Institute for International and Security Affairs, Berlin, Germany

(4) New South Wales Department of Primary Industries, NSW, Australia

(5) University of New England, Armidale, NSW, Australia

(6) Climate Change Institute, Australian National University, Canberra, Australia

* To whom correspondence should be addressed: j.rogelj@imperial.ac.uk

Five years ago, the UN Paris Agreement (https://unfccc.int/process-and-meetings/the-parisagreement/the-paris-agreement) set a ceiling for global warming at well below 2 degrees Celsius, ideally 1.5 degrees. World leaders also agreed to balance greenhouse gas emissions in the second half of the century so that the sum of all emitted and sequestered greenhouse gases from human activities is zero. Ever more countries, institutions and companies are announcing net-zero targets ${ }^{1,2}$ to align with this commitment. Recent examples include the US, China, the EU, Microsoft and an alliance of European airports. These are welcome signs of intent. They also come with difficulties.

Plans are hard to compare, and definitions loose. The details behind 'net-zero' labels differ enormously. Some targets focus solely on carbon dioxide $\left(\mathrm{CO}_{2}\right)$. Others cover all greenhouse gases. Companies may consider only emissions under their direct control, or also include those from their supply chains and from the use or disposal of their products. Sometimes the targets do not aim to reduce emissions but compensate them with offsets instead.

Important questions are being overlooked. Should some sectors, like electricity generation, reach net-zero earlier to counterbalance harder-to-abate sectors like heavy industry? Is it fair to expect emerging economies to follow the same net zero schedule as long-industrialized ones? Without careful attention to such issues, individual achievements risk not being strong enough to deliver the Paris Agreement's collective climate goal.

Critics may argue that it is better to have vague targets than to have none. But the stakes are too high to take comfort in mere announcements. Everyone need not make the same choices. 
Manuscript published in Nature - Rogelj, J., Geden, O., Cowie, A., Reisinger, A., 2021. Net-zero emissions targets are vague: three ways to fix. Nature 591, 365-368. https://doi.org/10.1038/d41586-021-00662-3

But without improved clarity, strategies behind net-zero targets cannot be understood and their impact can't be evaluated.

Governments and companies need to provide more detail and justify their net-zero targets. A key benchmark for this will be the next UN climate summit in Glasgow, Scotland, in November 2021, where countries will present new climate pledges. Otherwise, the global impact of net-zero targets cannot be properly assessed.

Here we call on nations, companies, and researchers advising them to clarify 3 aspects of their net-zero targets: the scope of their commitments; how they are deemed adequate and fair; and a concrete roadmap towards and beyond net-zero.

\section{Scope:}

It is vital that targets specify which emission sources and which gases are covered $\left(\mathrm{CO}_{2}\right.$, all greenhouse gases, or a subset); when net-zero will be reached, and whether the intent is to reduce, remove or offset the emissions.

The choice of gases affects the climate outcome. $\mathrm{CO}_{2}$ is the main cause of rising global temperatures; it lasts hundreds to thousands of years in the atmosphere and builds up. Bringing $\mathrm{CO}_{2}$ emissions down to net-zero halts further warming, but the impact of $\mathrm{CO}_{2}$ already present in the atmosphere will linger for centuries. By contrast, shorter-lived greenhouse gases, like methane, last for years to decades. Reducing them would diminish their contribution to warming relatively quickly, but eliminating their emissions is impossible at present. In addition, unlike with $\mathrm{CO}_{2}$, there are currently no technologies to actively remove them from the atmosphere.

Each country or organization takes a different tack. The EU targets all greenhouse gases by 2050. China's net-zero plan focuses on balancing $\mathrm{CO}_{2}$ emissions only, by 2060 . The BidenHarris climate plan for the US aims to reach net-zero across the economy by 2050, but has yet to say which gases are covered. The Paris Agreement considers all greenhouse gases, and emissions that cannot be eliminated have to be balanced by removing an equivalent amount of $\mathrm{CO}_{2}$ from the air. The UN has agreed a metric to determine this equivalent amount: the greenhouse gas' Global Warming Potential over 100 years or GWP 100 (https://unfccc.int/sites/default/files/resource/cma2018_3 add2_new_advance.pdf).

All available Paris-compatible pathways to meet net-zero greenhouse gas emissions use a combination of three strategies: rapid and large reductions in $\mathrm{CO}_{2}$ emissions, additional deep reductions in emissions of non- $\mathrm{CO}_{2}$ greenhouse gases, and a ramping up of strategies to remove $\mathrm{CO}_{2}$ from the air. This universal approach is illustrated for one specific pathway in Figure 1. More generally, across IPCC $1.5^{\circ} \mathrm{C}$ pathways, net-zero $\mathrm{CO}_{2}$ emissions are reached around 2050 (2046-2055, interquartile range), while net-zero greenhouse gas emissions are reached 1 to 2 decades later (2061-2084). ${ }^{3}$

Because $\mathrm{CO}_{2}$ removal is used to balance other, shorter-lived greenhouse gases, the Paris Agreement's net-zero greenhouse gas target will achieve more than stabilizing warming: temperatures will peak and slowly decline $e^{4,5}$ (Fig 1). But the balance is delicate: change the metric or gases covered, the speed at which various gases are reduced, or the proportion of reduction versus removal, and the peak and rate of temperature decline can be very different ${ }^{5}$. Temperature may even not decline at all. 
Vague terms abound. For example, 'carbon neutral' and 'climate neutral' are often-used but unhelpful labels. Sometimes they are synonyms for net-zero $\mathrm{CO}_{2}$ and net-zero greenhouse gas emissions, respectively. But not always. France's strategy for instance speaks of carbon neutrality but spans all greenhouse gases. Consistency, clarity and accuracy are required.

The scope of the sources of emissions covered also varies. Company targets might only cover emissions resulting from their direct activities; or they may also include emissions across their value chains. For example, Scandinavian furniture giant IKEA has a net zero target that includes all emissions from their entire supply chain (https://about.ikea.com/en/sustainability/becoming-climate-positive/what-is-climatepositive). So does Microsoft, who by 2050 also plans to neutralise all $\mathrm{CO}_{2}$ it emitted since its founding in 1975 (https://blogs.microsoft.com/on-the-issues/2020/07/21/carbon-negativetransform-to-net-zero/). On the other hand, ACI Europe, representing over 500 European airports, has set a net-zero $\mathrm{CO}_{2}$ target by 2050 that covers just buildings and operations on land, not emissions from airplanes. As a result, only $2 \%$ of emissions of all aviation activities that pass through these airports are addressed (https://www.aci-europe.org/netzero).

The anticipated role of $\mathrm{CO}_{2}$ removals also needs more clarity. Net-zero targets should declare how they will combine emissions reductions, direct $\mathrm{CO}_{2}$ removals (under direct control of the organisation or entity claiming the removal) and offsets (purchased credits for emissions reductions or removals carried out by someone else, elsewhere). On the whole, it's preferable to reduce emissions, because strategies for removal or offsetting often have uncertain effectiveness and may come with additional risks.

For example, some solutions require a lot of land, which can have knock-on impacts on biodiversity, food and water security — planting a forest, for example, may displace agriculture, and planting monoculture energy crops may reduce species diversity. The permanence of such biological removals remains uncertain: the long-term carbon storage capacity of forests and soils is not well known, and there can be no guarantee that a forest won't later be logged, devastated by a forest fire, or altered by climate change ${ }^{6}$.

Engineered solutions - such as using chemical filters to suck $\mathrm{CO}_{2}$ from the air for it to be piped underground - are still nascent. Deploying such technologies on a scale large enough to have a global impact remains speculative. Ultimately, costs and social acceptance might limit any $\mathrm{CO}_{2}$ removal option, for example, if communities oppose landscapes being transformed or $\mathrm{CO}_{2}$ being stored beneath their homes ${ }^{6}$. Net-zero declarations should say how these risks will be managed.

\section{Adequacy and fairness}

Countries and companies that set net-zero targets generally assume, and sometimes claim, that these are adequate to meet the global goals of the Paris Agreement. However, this involves implicit assumptions about what a fair contribution would be and what others should contribute. Ethical judgments are unavoidable, even if unvoiced.

What is considered "fair" differs across countries. All are in different stages of development, with a variety of opportunities, financing and resources available, and differing contributions to global warming. For example, Singapore is tiny, densely populated, and with limited potential to deploy renewables, but also rich and with high capacity to finance action. Europe has been contributing to global warming for over a century and was heavily deforested in the 
past, which means it now has significant potential for reforestation. Yemen has some of the best solar energy resources in the world, but as a least-developed country experiencing ongoing unrest it has no access to the necessary investments. Similar diversity applies to sectors. The agriculture and forestry sector has clear opportunities for $\mathrm{CO}_{2}$ removals; aviation and metals industries don't.

Net-zero targets defined using metrics other than $\mathrm{GWP}_{100}$ also shift the mitigation burden between gases, and thus between sectors and countries ${ }^{5,7-9}$. Weighting methane emissions less would make it easier for countries with considerable agricultural methane emissions to claim that net-zero is reached. However, this would also result in more global warming unless other countries - with mainly $\mathrm{CO}_{2}$ emissions - agree to reach net zero sooner.

Climate policies can be win-win, but emission targets are a null-sum game. If one country or company does less, others have to do more to achieve the same global temperature outcome. If a country takes 2060 as its domestic $1.5^{\circ} \mathrm{C}$ target, for example, it implicitly expects that all other countries together reach net-zero $\mathrm{CO}_{2}$ before the global average of around 2050.

Parties to the Paris Agreement should proactively disclose why they consider their net-zero targets to be fair and adequate. This is currently requested for near-term national mitigation targets (the Nationally Determined Contributions or NDCs) but not yet for longer-term targets like net zero.

Fairness issues also arise over carbon offsets. Cheap offsets can mean that a company makes limited effort to address its own emissions. Offsetting emissions through projects in another country means that any social and environmental risks of these projects are also outsourced. Finally, avoiding double-counting of offsets is a challenge-for example, if a reforestation project in Sierra Leone sells an offset credit to Microsoft, this emission reduction is doublecounted if it is also included towards Sierra Leone's emission target. The climate, obviously, sees the benefit only once. Trade in manufactured goods, energy products and renewable energy certificates complicates the picture of who is responsible for what. These aspects need to be explicitly considered and acknowledged. On the whole, it's preferable to deal with emissions locally rather than offsetting them elsewhere. Continued reliance on offsets may become increasingly unrealistic and ultimately unfair to countries that provide the offsets but cannot count those actions towards their own targets.

A key test for both fairness and adequacy is to apply the same logic underpinning any given net-zero target to other nations or companies. Would the world still hit net-zero if everyone applied the same logic? Would the same logic applied to other countries be fair to those countries?

Self-interests cannot be avoided: countries often choose fairness principles that favour their situation, resulting in countries overestimating how much their actions contribute to the global goal. Modelling work has shown, for example, that if all countries pursue the targets they themselves deem to be fair and in line with $1.5^{\circ} \mathrm{C}$, warming would hit $2.0^{\circ} \mathrm{C}$ instead ${ }^{10}$. This is why rigour and transparency are needed to support conversations about what is and isn't fair in light of a collective, global target.

\section{Long term roadmap}


Net zero targets are more credible if they include milestones, an implementation plan, and a statement about longer-term intent for either maintaining net-zero or going net-negative. Leaving these out risks inaction, diversions, and failure.

For example, the UK announced in 2019 that it would balance emissions by 2050, but its near-term policies were still off track. In 2020, it then published its first NDC for 2030, together with other policy milestones. Together, these now present a more feasible domestic net-zero plan.

Net-zero targets are not end points. They are themselves milestones and play a role in meeting net-negative emissions targets further down the road ${ }^{11}$. Few net zero targets explicitly consider this, but it determines how net-zero is best approached.

Those most able to reach a net-negative future need to plan for it now-not out of generosity but as a fair and equitable contribution towards a collective, global net-zero target. Finland and Sweden, for example, have targets for reaching net-zero greenhouse gas emissions by 2035 and 2045, respectively, and going net-negative thereafter. In the context of an EU-wide net-zero target for 2050, these intentions can compensate for the weaker reductions of other EU members with greater technical or political obstacles.

Finally, targets must be amenable to tightening. As we increasingly experience a warmer world, nations and companies might decide that action should be taken more rapidly ${ }^{12}$. Acceleration can be encouraged by setting a regular schedule for review and re-assessment of targets, such as already in place for the shorter-term NDCs.

Microsoft's carbon-negative pledge is one good example of long-term thinking: it has a commitment to be carbon negative by 2030 , and a portfolio approach involving a $\$ 1$ billion investment fund to develop and deploy new $\mathrm{CO}_{2}$ reduction and removal technologies. The underdeveloped market for corporate procurement of $\mathrm{CO}_{2}$ removals means their plan will undoubtedly undergo updates as time passes.

Critics may question the value of discussing a roadmap to net-negative emissions when the world is not even on track to achieve net-zero. However, these conversations are vital in shaping a sustainable long-term future for our shared planet.

\section{Next steps}

As more and more countries and companies work towards net-zero targets, it is vital that rigour and clarity be added to their presentation so they can be evaluated and assessed. To contribute to the Paris Agreement's global net-zero goal, targets need to have a clear scope; they must pay explicit attention to transparency, fairness, and equity; and a roadmap to achieve these targets needs to be laid out with clear milestones to hit, and a pathway to take them beyond net-zero where possible. A checklist to support the development of more rigorous and clearer targets is provided in Box 1 and the Supplementary Material.

Researchers can help - first and foremost by demanding transparency, but also by engaging at the science-policy interface. In the area of 'scope', for example, nature-based carbon sinks are used for direct removals or offsetting. Risks surrounding their future reliability or potential reversal under climate change have to be better understood, together with their wider social and ecological consequences. These should be incorporated in contingency plans. 
The area of 'fairness' is ripe for interdisciplinary work. Net-zero targets at the country or company level cannot be set based on natural science or economics alone. Ethicists and social scientists are needed, including to explore how fairness concepts apply to today's multinational corporations - which span multiple countries, sectors, and reach staff with incomes ranging from the lowest to the highest. The understanding of fairness must be mainstreamed, including in tools used to design net-zero targets so that countries and companies can see the big picture implications of their own assumptions and decisions.

The UN review process for detailing near-term NDCs, assessing and revising them every 5 years provides a good starting point that can be extended to include longer-term net-zero targets. Companies should do the same and apply a standardized review process, considering the aspects we have outlined here, to grade the quality of their net-zero targets.

Today's net-zero targets are only the start of a long journey towards a safer world. 
Manuscript published in Nature - Rogelj, J., Geden, O., Cowie, A., Reisinger, A., 2021. Net-zero emissions targets are vague: three ways to fix. Nature 591, 365-368. https://doi.org/10.1038/d41586-021-00662-3

\section{BOX: Check list for rigorous and clear net-zero plans}

Scope

- What global climate or temperature goal is this plan aiming to contribute to?

- Is the goal to peak and decline, or stabilize global temperature?

- What is the target date for net-zero?

- Which greenhouse gases are being considered?

- How are greenhouse gases being aggregated (GWP-100 or another metric)?

- What is the scope of the emissions (over which territories, time frames or activities)?

- What are the relative contributions of reductions, removals and offsets?

- How will you ensure that removal and offset plans deliver?

Adequacy \& fairness

- What fairness principles are being applied?

- Would those principles achieve the global climate goal if they were applied universally?

- What are the fairness consequences for others of applying those principles universally?

- How is your target likely to impact the capacity of others to achieve net-zero, and impact their pursuit of other Sustainable Development Goals (SDGs)?

Roadmap

- What milestones and policies will support achievement of net-zero?

- What monitoring and review system will be used to assess progress and revise the target?

- Will net-zero be maintained, or is it a step towards net-negative?

"The views expressed in this paper are those of the authors and do not necessarily reflect those of their institutions." 


\section{Figure 1 |}

Different net-zero targets have different implications. All pathways reaching net-zero $\mathrm{CO}_{2}$ or net-zero greenhouse gas emissions use three linked strategies. These are illustrated for one of the illustrative pathways of the IPCC Special Report on Global Warming of $1.5^{\circ} \mathrm{C}$ (top panel). In this pathway, net-zero $\mathrm{CO}_{2}$ emissions are achieved in the late $2050 \mathrm{~s}$, while net-zero for all greenhouse gases are achieved only around 2070 (middle panel, black and blue lines, respectively). Global temperature peaks roughly at the time of net-zero $\mathrm{CO}_{2}$ and declines under net-zero GHG (bottom panel). Maximum global temperature increase is around $1.6^{\circ} \mathrm{C}$. Choosing different gases, different timing for net-zero emissions, and different methods to aggregate emissions, can have very different outcomes. 
Manuscript published in Nature - Rogelj, J., Geden, O., Cowie, A., Reisinger, A., 2021. Net-zero emissions targets are vague: three ways to fix. Nature 591, 365-368. https://doi.org/10.1038/d41586-021-00662-3

Global greenhouse gas (GHG) emissions
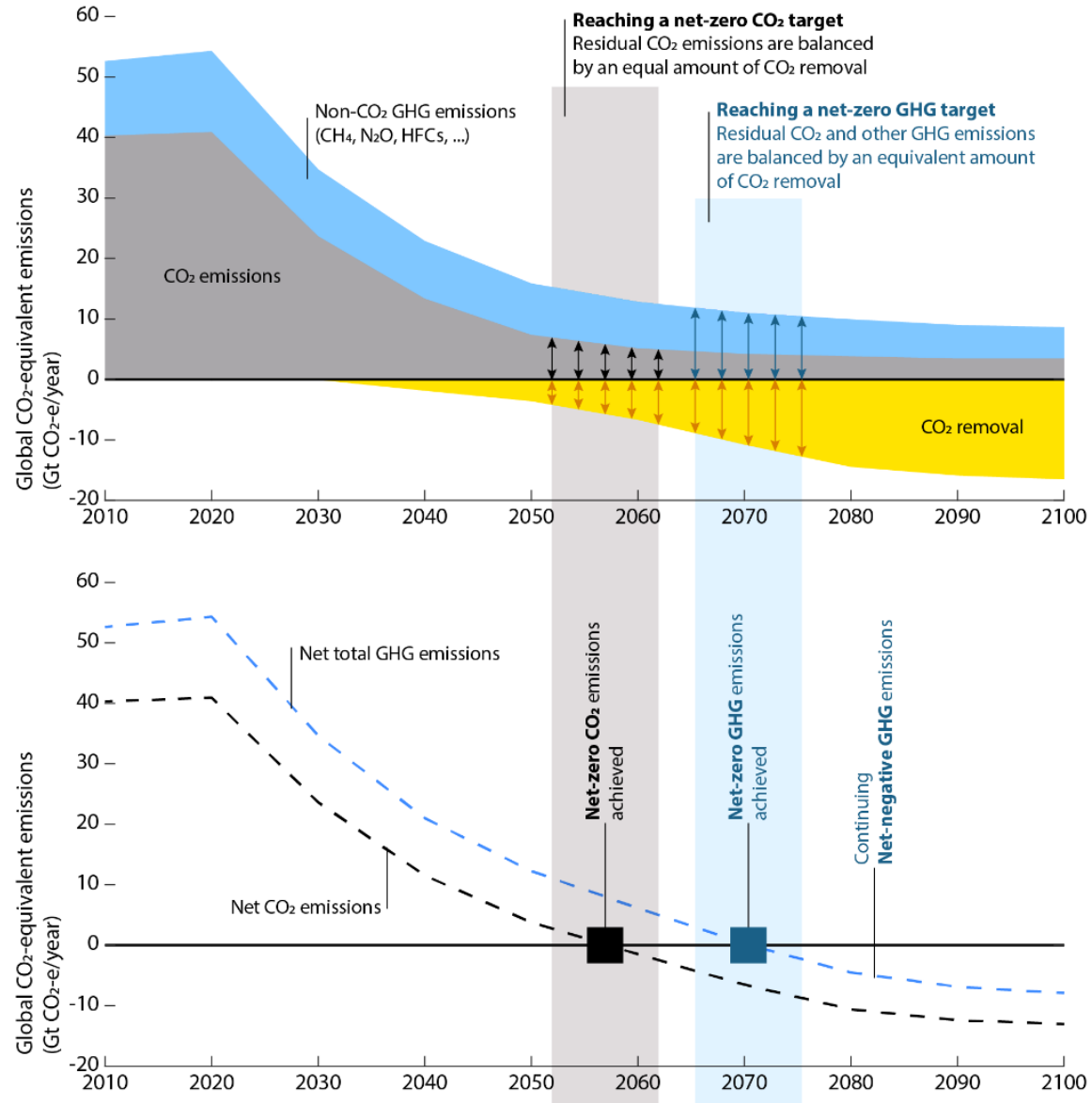

Global warming implications

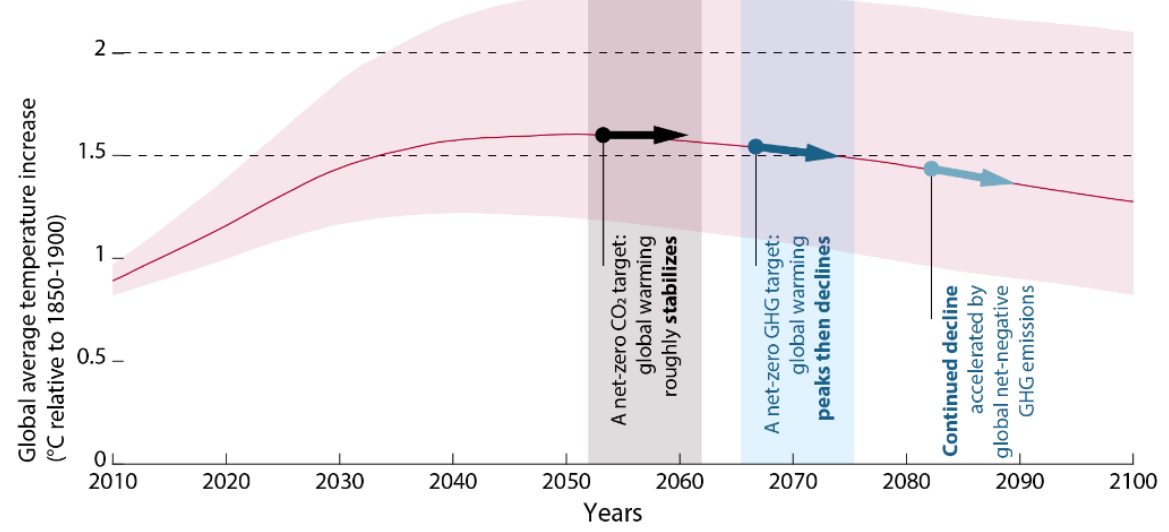


Manuscript published in Nature - Rogelj, J., Geden, O., Cowie, A., Reisinger, A., 2021. Net-zero emissions targets are vague: three ways to fix. Nature 591, 365-368. https://doi.org/10.1038/d41586-021-00662-3

\section{References}

1. Rogelj, J. et al. Zero emission targets as long-term global goals for climate protection. Environmental Research Letters 10, 105007 (2015).

2. Geden, O. An actionable climate target. Nature Geoscience 9, 340 (2016).

3. Rogelj, J. et al. Mitigation pathways compatible with $1.5^{\circ} \mathrm{C}$ in the context of sustainable development. in Global Warming of $1.5^{\circ} \mathrm{C}$ : an IPCC special report on the impacts of global warming of $1.5^{\circ} \mathrm{C}$ above pre-industrial levels and related global greenhouse gas emission pathways, in the context of strengthening the global response to the threat of climate change, sustainable development, and efforts to eradicate poverty (eds. Flato, G., Fuglestvedt, J., Mrabet, R. \& Schaeffer, R.) 93-174 (IPCC/WMO, 2018).

4. Tanaka, K. \& O’Neill, B. C. The Paris Agreement zero-emissions goal is not always consistent with the $1.5^{\circ} \mathrm{C}$ and $2^{\circ} \mathrm{C}$ temperature targets. Nature Climate Change (2018) doi:10.1038/s41558-018-0097-x.

5. Fuglestvedt, J. et al. Implications of possible interpretations of 'greenhouse gas balance' in the Paris Agreement. Philosophical Transactions of the Royal Society A: Mathematical, Physical and Engineering Sciences 376, (2018).

6. IPCC. Summary for Policymakers. in Climate Change and Land: an IPCC special report on climate change, desertification, land degradation, sustainable land management, food security, and greenhouse gas fluxes in terrestrial ecosystems (eds. Shukla, P. R. et al.) 141 (2019).

7. Rogelj, J. \& Schleussner, C.-F. Unintentional unfairness when applying new greenhouse gas emissions metrics at country level. Environmental Research Letters 14, 114039 (2019). 
Manuscript published in Nature - Rogelj, J., Geden, O., Cowie, A., Reisinger, A., 2021. Net-zero emissions targets are vague: three ways to fix. Nature 591, 365-368. https://doi.org/10.1038/d41586-021-00662-3

8. Brennan, M. E. \& Zaitchik, B. F. On the potential for alternative greenhouse gas equivalence metrics to influence sectoral mitigation patterns. Environmental Research Letters 8, 014033 (2013).

9. Lynch, J., Cain, M., Pierrehumbert, R. \& Allen, M. Demonstrating GWP*: a means of reporting warming-equivalent emissions that captures the contrasting impacts of short- and long-lived climate pollutants. Environ. Res. Lett. 15, 044023 (2020).

10. Robiou du Pont, Y. \& Meinshausen, M. Warming assessment of the bottom-up Paris Agreement emissions pledges. Nature Communications 9, 4810 (2018).

11. Rogelj, J. et al. A new scenario logic for the Paris Agreement long-term temperature goal. Nature 573, 357-363 (2019).

12. Obersteiner, M. et al. Managing Climate Risk. Science 294, 786b-7787 (2001). 